\title{
The comparison of single plate and double plate fixation methods for treatment of humeral shaft nonunions
}

\author{
Osman Tecimel, MD (1), İbrahim Bozkurt, MD (D), Şahin Çepni, MD (D), Fırat Yaman, MD (D), \\ Ahmet Fırat, MD Di), Durmuş Ali Öçgüder, MD (D) \\ Department of Orthopedics and Traumatology, Ankara City Hospital, Ankara, Turkey
}

Humerus diaphyseal fractures constitute 1 to $3 \%$ of all fractures and $20 \%$ of humerus fractures. ${ }^{[1]}$ There are several conservative and surgical methods in the treatment of humerus shaft fractures. Although it is possible to achieve good results in the majority of fractures with conservative methods, rates of pseudoarthrosis of 8 to $12 \%$ in humerus shaft fractures have been reported in the literature, and nonunion rates are higher particularly in patients with proximal shaft fracture and butterfly fragment. ${ }^{[2]}$

Biological fixation and surgical traditional plating are acceptable alternatives at a higher rate than intramedullary and external fixation methods. ${ }^{[3,4]}$ Despite all these options, the union rate is 82 to $95 \%$. Probable reasons for surgical failure are inadequate fixation, devitalization of bone fragments, infection, osteopenia, and bone defects. ${ }^{[5,6]}$ In the nonunion of humerus shaft fractures, morbidity is frequently associated with shoulder and elbow joint stiffness,

Received: March 31, 2020

Accepted: June 17, 2020

Published online: January 06, 2021

Correspondence: İbrahim Bozkurt, MD. Göksu Mah. Selçuklular Cad. Göksupark Konutları J/58, 06570 Etimesgut, Ankara, Türkiye.

E-mail: dr.bozkurtibrahim@gmail.com

Doi: $10.5606 /$ ehc. 2021.74488

Citation: Tecimel O, Bozkurt I, Ceepni Ș, Yaman F, Fırat A, Öçgüder DA. The comparison of single plate and double plate fixation methods for treatment of humeral shaft nonunions. Jt Dis Relat Surg 2021;32(1):67-74.

(อ2021 All right reserved by the Turkish Joint Diseases Foundation

This is an open access article under the terms of the Creative Commons Attribution-NonCommercial License, which permits use, distribution and reproduction in any medium, provided the original work is properly cited and is not used for commercial purposes (http://creativecommons.org/licenses/by-nc/4.0/).

\section{ABSTRACT}

Objectives: This study aims to evaluate the early- and mid-term shoulder and elbow functions and compare the union rates after the application of single plate and double plate for the treatment of humerus shaft nonunions.

Patients and methods: This retrospective study included 56 patients (36 males, 20 females; mean age 53.8 \pm 9.5 ; range, 28 to 68 years) treated with double plate $(\mathrm{n}=25)$ and single plate $(n=31)$ osteosynthesis between October 2012 and January 2016. Surgical treatment of the nonunion was applied in the fourth month after the fracture at the earliest. Autograft taken from the iliac bone was applied during the surgery in all patients. Evaluation was performed using The University of California at Los Angeles (UCLA) Shoulder Score, Mayo Elbow Performance Score (MEPS), Visual Analog Scale (VAS), Constant Shoulder Score, and Disabilities of the Arm Shoulder and Hand (DASH) questionnaire.

Results: The mean postoperative follow-up time was $40.7 \pm 9.6$ (range, 25 to 58) months. No statistically significant difference was determined in respect of time to union, follow-up time, DASH questionnaire score, UCLA Shoulder Score, VAS, MEPS and Constant Shoulder Score after union in the comparison of the two groups $(p>0.05)$. In the examination of postoperative early (three months) recovery phase of shoulder and elbow functions, statistically significant superior scores were obtained in the double plate group for MEPS (double plate median=85 [ $\min 75-\max 90$ ], single plate median=75 [min 70-max 85]) and Constant Shoulder Score (double plate median $=89$ [min $85-\max 92]$, single plate median $=81[\min 75-\max 90])(\mathrm{p}<0.001)$.

Conclusion: There was no statistically significant difference in terms of time to union and union rates between single plate and double plate fixations for surgical treatment of humeral shaft nonunions. However, superior clinical results were obtained in the early recovery phase of shoulder and elbow functions with double plate fixation.

Keywords: Double plate, humerus shaft fracture, nonunion, single plate.

pain, and weakness. For a functional upper extremity, it is important that union within acceptable limits is provided. ${ }^{[6]}$ 
During the treatment of humerus shaft nonunion and after healing, various problems may be seen in shoulder and elbow functions. The hypothesis of the current study was that the treatment option selected would affect union rates and shoulder and elbow functions in the early- and mid-term. Therefore, in this study, we aimed to evaluate the early- and mid-term shoulder and elbow functions and compare the union rates after the application of single plate and double plate for the treatment of humerus shaft nonunions.

\section{PATIENTS AND METHODS}

This retrospective study included 56 patients (36 males, 20 females; mean age 53.8 \pm 9.5 ; range, 28 to 68 years) operated on for a diagnosis of humerus shaft fracture nonunion at Ankara City Hospital between October 2012 and January 2016 (Table I). Patients were excluded from the study if they had a pathological fracture, atrophic pseudoarthrosis, open fracture, infected nonunion; fractures managed with soft tissue or vascular reconstruction, any chronic disease, or if they did not have functional results available. Also, patients with restricted range of motion in the shoulder and/or elbow joint of the ipsilateral side due to previous surgery or any musculoskeletal disease were excluded. The study protocol was approved by the Ankara City Hospital Ethics Committee (March 2020, number: 72300690-799). A written informed consent was obtained from each patient. The study was conducted in accordance with the principles of the Declaration of Helsinki.

Since 2012, the information of all patients with a humerus fracture has been recorded in our clinic. Data were collected from the patient records including demographic data, mechanism of fracture, fracture localization, time to fracture union, indications for surgical treatment, complications that developed during treatment, and any preoperative radial nerve injury. The fractures were classified according to the Arbeitsgemeinschaft für Osteosynthesefragen (AO)/Association for the Study of Internal Fixation (ASIF) classification systems (Table II).

Treatment with single plate or double plate was applied to patients diagnosed with nonunion based on the absence of radiological findings of union from the fourth month after the first treatment up to the sixth month, loss of stability associated with implant failure, and complaints of pain accompanying pathological movement in the fracture region.

The patients were separated into two groups according to the treatment method. Double plate group patients $(n=25)$ were treated with double plate osteosynthesis, while single plate group patients $(n=31)$ were treated with single plate osteosynthesis. Patients who applied to the outpatient clinic with nonunion of humeral shaft fracture were treated with a single plate or double plate fixation without any additional criteria by a single surgeon experienced in psodoarthrosis surgery. There were no additional criteria for single or double plate fixation. The treatment choice on whether applying single or double plate fixation was made randomly. However, patients with hardworking manual labor or intense musculature on upper extremities had a priority for applying double plate fixation. In the double plate group, 20 patients were primarily treated with conservative methods with cast and five patients with open reduction and internal fixation (ORIF). In the single plate group, 25 patients were primarily treated with conservative treatment with cast and six patients with ORIF. All of the 11 patients of ORIF were treated with a single plate.

Under general anesthesia, the patients were positioned in the beach-chair position. Antibiotic prophylaxis of $1000 \mathrm{mg}$ cefazolin was administered. An anterolateral incision was used in both groups, and then the radial nerve was dissected and suspended. The implants remaining from the previous operation were removed. Debridement was applied until bleeding bone ends were obtained in the nonunion region, then the medullar canal was opened and decortication was performed. Although no deep infection was observed in any patient, soft tissue was taken for cultures and pathology examination. In the patients applied with double plate, the plates were placed to be angled at $90^{\circ}$ to the anterior and lateral surfaces.

In the patients with a single plate fixation, the plate was placed on the anterolateral humeral surface. Autogenous bone grafting taken from the iliac bone was applied to all patients. In addition to the autogenous graft, allograft (calcium phosphate granule bone chips) was used in five patients applied with double plate and four patients applied with single plate.

In the majority of the double plate group patients, $4.5 \mathrm{~mm}$ limited contact dynamic compression plates (LC-DCPs) (Double Medical Technology Inc., Xiamen, China) with five to 10 holes were used. In one patient with a proximal shaft fracture, a Philos ${ }^{\circledR}$ Long Plate (Double Medical Technology Inc., Xiamen, China) was applied. In all patients in the single plate group, a 4.5 mm LC-DCP was used with $4.5 \mathrm{~mm}$ cortical screws. After anatomic reduction of the bone parts, at least 


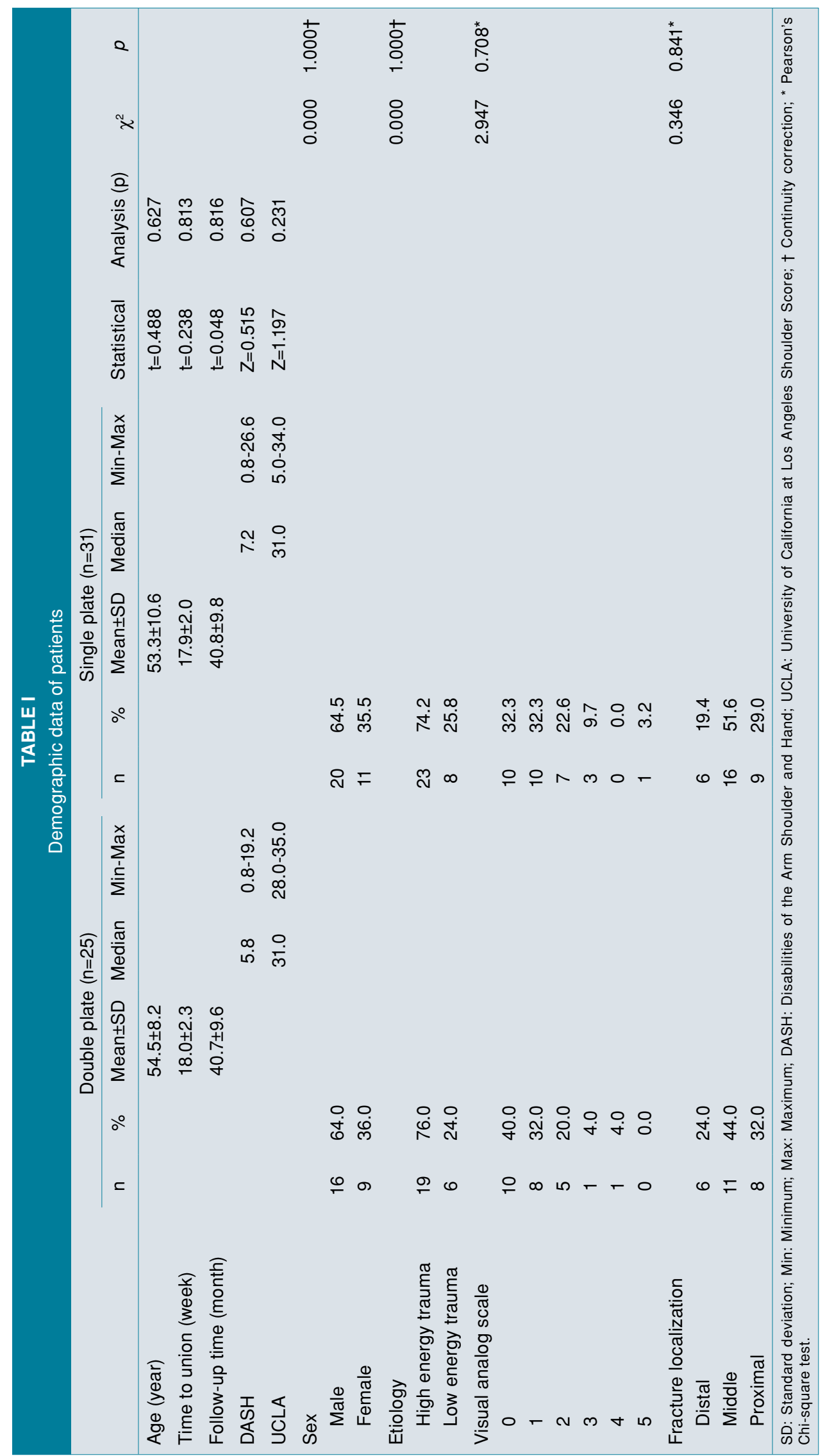




\begin{tabular}{|ccc|}
\multicolumn{3}{|c|}{$\begin{array}{c}\text { TABLE II } \\
\text { Distribution of humerus shaft fracture by }\end{array}$} \\
Arbeitsgemeinschaft für Osteosynthesefragen classification
\end{tabular}

six levels of cortical fixation were obtained on both sides of the fracture line with the main anterolateral plate (Figure 1). The second plate was applied with the aim of supporting buttress effect. In order to limit damage to the soft tissues further, six-cortex fixation rule was not applied on this posterolateral side of the fracture. The radial nerve was protected throughout the operation. On postoperative third day, passive hand wrist, elbow and pendular shoulder movements were started. The patients were instructed to perform active elbow and shoulder movements as tolerated. Weight lifting was not permitted until radiological union was confirmed. Union was evaluated clinically as no pain in the fracture line and radiologically as the visualization of bridging callus in at least three cortices on anteroposterior and lateral radiographs.

Evaluation was performed for the union and complication rates using The University of California at Los Angeles (UCLA) Shoulder Score, Mayo Elbow
Performance Score (MEPS), Constant Shoulder Score, and Disabilities of the Arm Shoulder and Hand (DASH) questionnaire, as objective and functional clinical results. The time of return to pre-injury work and activities was also questioned.

\section{Statistical analysis}

Statistical analysis was performed using the IBM SPSS version 25.0 software (IBM Corp., Armonk, NY, USA). Conformity of continuous variables, such as age, time to union, follow-up time, DASH questionnaire score and UCLA Shoulder Score, to normal distribution was assessed with the Shapiro-Wilk test and graphic methods. Data conforming to normal distribution were stated as mean \pm standard deviation, and variables not showing normal distribution as median (min-max) values. Categorical variables such as sex, visual analog scale (VAS), and etiology were stated as number (n) and percentage (\%). To examine the changes in continuous variables, the independent samples t-test was applied to those showing normal distribution and the Mann-Whitney $U$ test to those with non-normal distribution. Changes in the groups of categorical variables were examined with the chi-square and Pearson's chi-square tests and continuity correction. A value of $\mathrm{p}<0.05$ was accepted as statistically significant.

\section{RESULTS}

In the comparison of the demographic data of the groups, the mean age was $54.5 \pm 8.2$ (range, 38 to 68) years in the double plate group and $53.3 \pm 10.6$ (range, 28 to 67 ) years in the single plate group. The age distribution of the groups was determined to be similar $(\mathrm{t}=0.488, \mathrm{p}=0.627)$. Sex distribution was similar as $64.0 \%(\mathrm{n}=16)$ males and $36.0 \%(\mathrm{n}=9)$

\begin{tabular}{|c|c|c|c|c|c|c|}
\hline \multicolumn{7}{|c|}{ TABLE III } \\
\hline & \multicolumn{2}{|c|}{ Double plate } & \multicolumn{2}{|c|}{ Single plate } & \multicolumn{2}{|c|}{ Statistical analysis } \\
\hline & Median & Min-Max & Median & Min-Max & Z & $p$ \\
\hline \multicolumn{7}{|l|}{ Constant } \\
\hline Preoperative & 30.0 & $26.0-34.0$ & 30.0 & $21.0-36.0$ & 0.330 & 0.741 \\
\hline Postoperative $3^{\text {rd }}$ month & 89.0 & $85.0-92.0$ & 81.0 & $75.0-90.0$ & 5.450 & $<0.001$ \\
\hline After union & 92.8 & $87.0-97.0$ & 91.6 & $88.0-96.0$ & 1.067 & 0.440 \\
\hline \multicolumn{7}{|l|}{ MEPS } \\
\hline Preoperative & 30.0 & $20.0-35.0$ & 30.0 & $20.0-40.0$ & 0.919 & 0.358 \\
\hline Postoperative $3^{\text {rd }}$ month & 85.0 & $75.0-90.0$ & 75.0 & $70.0-85.0$ & 4.967 & $<0.001$ \\
\hline After union & 90.0 & $15.0-100.0$ & 90.0 & $70.0-100.0$ & 0.954 & 0.340 \\
\hline
\end{tabular}


females in the double plate group, and $64.5 \%(\mathrm{n}=20)$ males and $35.5 \%(n=11)$ females in the single plate group $\left(\chi^{2}=0.000, p=1.000\right)$.

Homogenous distribution of etiology was determined between the groups $\left(\chi^{2}=0.000, p=1.000\right)$ (Table I). No statistically significant difference was determined between the groups in respect of time to union ( $>0.05$ ).
In the postoperative third month evaluation of the Constant Shoulder Score and MEPS, statistically significant higher scores were obtained in the double plate group $(p<0.001)$ (Table III). When the Constant Shoulder Score and MEPS were examined after bone union, no statistically significant difference was determined between the groups $(p>0.05)$ (Table III). No statistically significant difference was determined between the groups in respect of
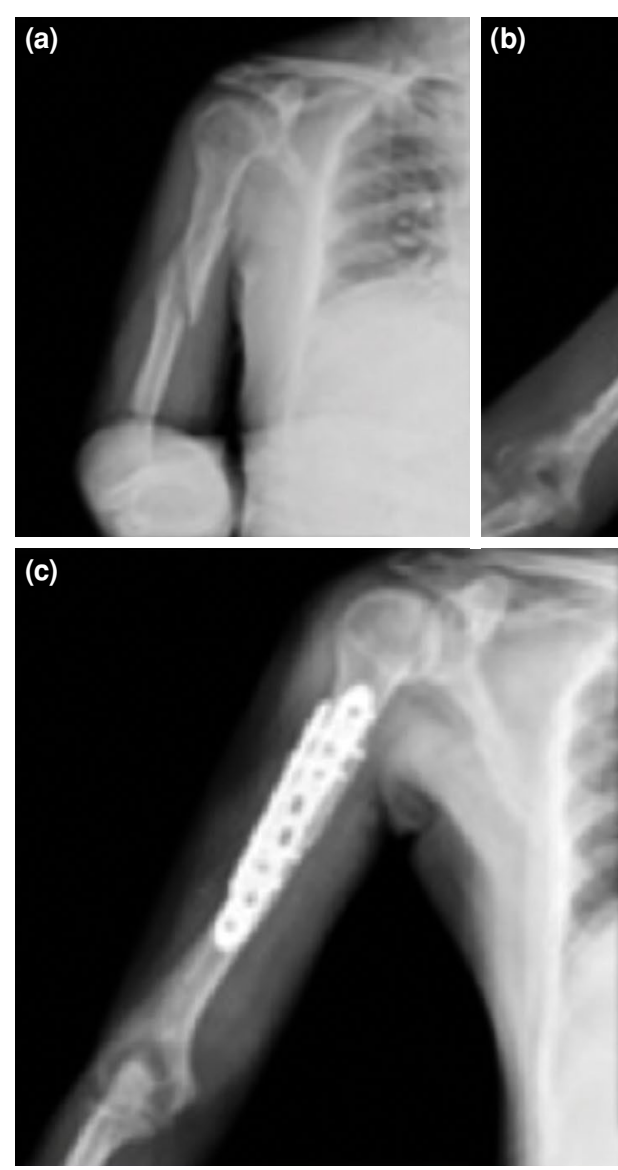
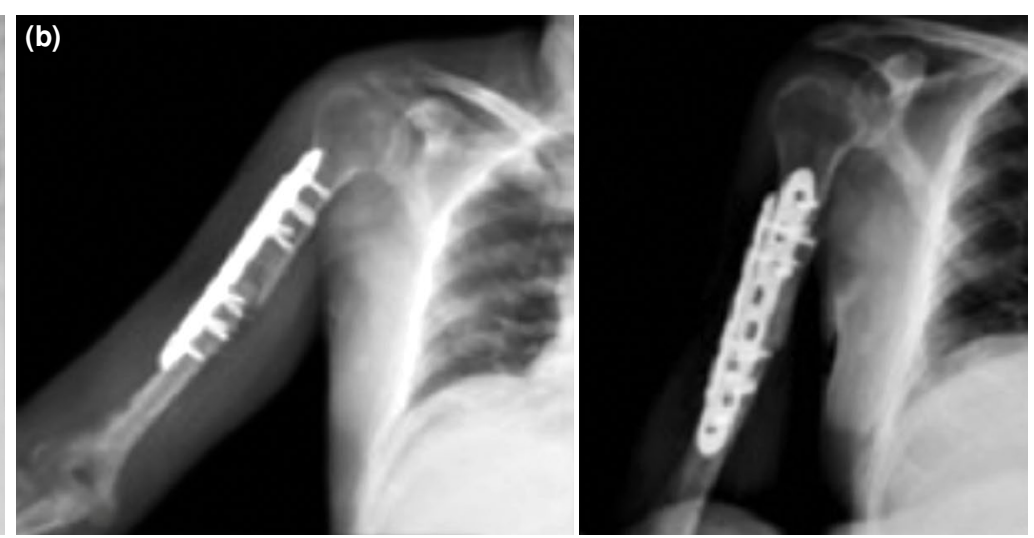

(d)

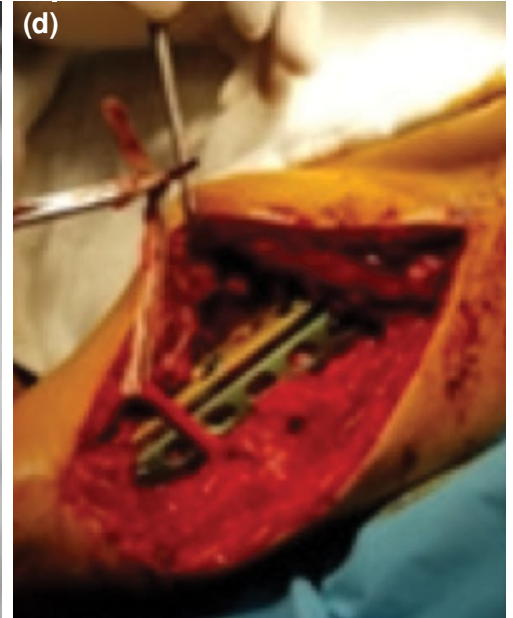

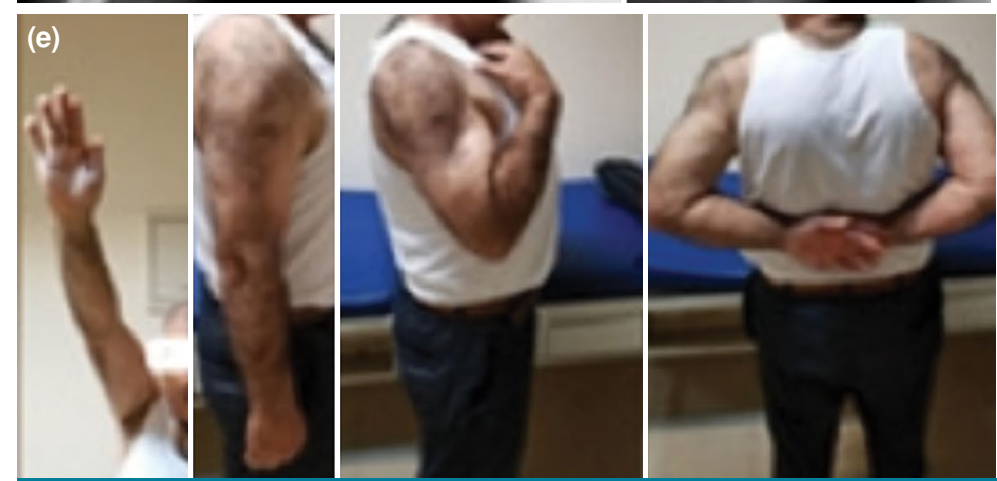

FIGURE 1. (a) Male patient with an oligotrophic diaphyseal humerus nonunion. Sixth month of conservative treatment after humerus fracture. (b) Early postoperative radiography of double plate surgery. (c) Final follow-up showing radiographic bony union. (d) Intraoperative image after double plate application. (e) Functional results in third year follow-up. 
the VAS values after bone union $(p=0.708)$. There was no significant difference between the groups in respect of the UCLA Shoulder Score and DASH questionnaire score $(p>0.05)$ (Table I).

Two patients in single plate group had implant failures on the fourth and sixth months of the surgeries. The former one was a smoking and obese patient, while the latter did not have any comorbidities. In total, three patients had limitation of shoulder joint movement and two of these were patients who had implant failure.

\section{DISCUSSION}

There are few studies in the literature related to the comparison of the applications of single plate and double plate in the treatment of humerus shaft fracture nonunion. Furthermore, these studies have not evaluated shoulder and elbow joint functions. This study demonstrated that in the early postoperative period of cases treated for nonunion of humerus shaft fractures, superior functional results of shoulder and elbow joints were obtained in patients applied with double plate fixation compared to those applied with single plate fixation. ${ }^{[7]}$ In humerus shaft fractures, shoulder and elbow functions must be protected until fracture healing. The regaining of shoulder and elbow functions is important in this patient group, as patients diagnosed with humerus shaft nonunion are followed-up for at least four to six months. In the current study, patients applied with double plate were seen to have regained shoulder and elbow functions in a shorter time. Therefore, the application of double plate can be selected for the patient group wishing to return to work early or for those who have limited shoulder and elbow functions.

Nonunion of humerus shaft fractures can be seen as a result of both conservative and surgical treatments. However, the treatment of nonunion seen following surgical stabilization is known to be more challenging. Various methods have been described for the treatment of humerus shaft fracture nonunion. The basic aim of treatment is to achieve bone union and a functional upper extremity within acceptable limits. The primary principle of treatment is to provide mechanical and biological support in the nonunion area of long bone fractures. In the current study, no implant failure or loss of fixation was observed in any of the patients applied with double plate, while implant failure and loss of fixation was seen in two patients applied with single plate fixation. Despite these two implant failures, the union rate in single plate group did not show any statistically significant difference compared to double plate group. This was due to the low implant failure number that was not sufficient to form a sample group for statistical analysis. Therefore, it was accepted as a not statistically significant difference.

There are several reasons for nonunion of humerus shaft fractures, primarily patient-related factors (advanced age, osteoporosis, impaired bone metabolism), ${ }^{[8]}$ fracture type (open fracture, fractures with bone loss), and surgical errors (insufficient fixation, incorrect implant selection). ${ }^{[9,10]}$ Implants that can be applied for fixation in cases of nonunion are intramedullary nailing, single plate, double plate, and Ilizarov frame.

Although intramedullary nailing seems to be a good option, some studies in the literature have reported that in comparison with plating, intramedullary nailing is not an appropriate fixation method for humerus shaft nonunion. ${ }^{[11,12]}$ The common point of these studies is that the application of nails of different properties does not provide adequate rotational stability. Moreover, they may cause rotator cuff damage, and pain and stiffness in the shoulder. ${ }^{[13]}$ In the current study, no significant restriction in shoulder movements was determined in any patient applied with double plate, whereas restriction in shoulder movements was determined in three patients applied with single plate in the early period (third month) of follow-up. This can be attributed to superior stability in the patients applied with double plate and therefore these patients adapted earlier and superiorly to the rehabilitation program.

In the literature, there are no large case series studies of humerus shaft fracture nonunion, and there are insufficient data about the functional shoulder and elbow scores of the patients. Sügün et al. ${ }^{[14]}$ evaluated 26 patients and reported the mean Constant Shoulder Score and MEPS after union to be 87.1 (range, 65 to 98) and 94.7 (range, 80 to 100), respectively. However, evaluation was not performed of early functional results. In the current study, there was no difference between the groups in the functional shoulder and elbow scores after full bone union, whereas in the early postoperative period (three months), the Constant Shoulder Score and MEPS were found to be significantly superior in the patient group applied with double plate. According to these results, it can be said that these patients regained shoulder and elbow functions more rapidly. 
Sufficient fixation can be obtained with an Ilizarov frame, even in cases with bone defect and osteopenia; ${ }^{[15]}$ however, there is a risk of pin tract infection and nerve damage. No infection developed in any of the patients in the current study. Although radial nerve neuropaxia developed postoperatively in one patient applied with double plate, this recovered in the ninth week of follow-up and did not create any significant restriction in respect of functional results. As radial nerve damage can have a negative effect on the shoulder and elbow rehabilitation of the patient, successful results can be obtained with appropriate programs applied to these patients until nerve functions are recovered.

Although compressive plating with at least eight points of cortical fixation with a $4.5 \mathrm{~mm}$ narrow plate and autologous bone graft is accepted as the gold standard treatment for humerus shaft nonunion, the union rate reported in the literature is approximately $90 \% .^{[5,16]}$ In cases with poor bone stock, the application of limited contact plate (LCP) cortical and locking screws allows superior compression of the fracture ends and reduces the pullout risk to a minimum. ${ }^{[15,17]}$ In nonunions with extensive tissue loss in particular and bone resorption developing after single plate application, a double plate provides longer survival. In a biomechanical, clinical study by Rubel et al., ${ }^{[17]}$ stronger stabilization was reported to be provided by double plate fixation compared to single plate fixation. However, this application technique is challenging due to the extensive soft tissue dissection required for the application of two plates which increases the risk of nonunion and nerve damage.

The use of short and long plates together avoids excessive stress on both ends. ${ }^{[18]}$ Prasarn et al. ${ }^{[19]}$ described double plate fixation for humerus distal third fractures. In a modified posterior approach, a 2.7 or $3.5 \mathrm{~mm}$ pelvic reconstruction plate was applied to the lateral humerus, and an extra-articular, hockey stick-shaped distal humerus locking plate was applied with a posterolateral approach. Excellent bone union with no complications was reported in 15 cases. Metikala and Bhogadi ${ }^{[20]}$ reported union in a humerus shaft nonunion after the use of plating at right angles to each other together with autologous bone graft. In the current study, complete union was achieved in all patients applied with double plate and in $92 \%$ of those applied with single plate. As we mentioned before, two implant failures did not cause any statistically significant difference between two groups due to the low number of patients.
In a biomechanical study by Kosmopoulos et al., ${ }^{[21]}$ three different single plates and one double plate were applied to mid-diaphyseal humerus fractures, and it was reported that superior torsional pressure, compression, and posterior anterior and lateral medial bending were achieved with short double plating compared to the nine-hole, $4.5 \mathrm{~mm}$ narrow plate. Also, two small double plates were seen to be superior to the nine-hole, $4.5 \mathrm{~mm}$ screw plate in respect of compression and lateral medial bending. With the exception of posterior anterior bending, the best load distribution property from screw to screw was seen in double plating. In our study, the double plate group had no plate or screw breakage while single plate group had two implant failures as plate breakage.

Lee $^{[22]}$ recently described treatment of humeral distal third fractures using a LCP metaphyseal plate with an anterolateral approach. When a single plate is used for ORIF, a larger plate may be required to provide stability, and this can require more skin and soft tissue dissection. For double plating, a smaller incision and smaller working area are sufficient. In distal diaphyseal fractures, the number of screws is limited, which causes imbalance in the load transfer between bone and plate, thereby increasing stress shielding. ${ }^{[23]}$ Capo et al. ${ }^{[24]}$ reported less time spent as one of the reasons supporting double plating rather than single plating. Various authors have suggested that the reduction plate made fixation of the other plate easier and could reduce the total operation time. ${ }^{[25-27]}$ In the current study, the mean operating time was $101 \pm 15.6$ (range, 76 to 125 ) $\mathrm{min}$ in patients applied with double plate and $93 \pm 15.2$ (range, 68 to 123) min in those applied with single plate.

Operative complications of humerus diaphyseal fractures are infection, nonunion, failed fixation, and reoperation. ${ }^{[28,29]}$ The advantage of double plating is a smaller skin incision and increased mechanical stability, which reduce the risk of these possible complications.

The subject investigated in the current study has not adequate evidence in the literature. However, this study has some limitations. Firstly, the number of patients in both study groups is low. Secondly, the study design is retrospective, and prospective randomized studies are needed for strong evidences about double plate fixation for humeral shaft nonunions.

In conclusion, although humerus diphyseal nonunion is still a severe problem, it is possible to 
obtain good functional results with the application of double plating and single plating in the treatment of humerus shaft fracture nonunion. In our study, there was no statistically significant difference in terms of time to union and union rates between single plate and double plate fixations for the surgical treatment of humeral shaft nonunions. However, superior clinical results were obtained in the early recovery phase of shoulder and elbow functions with double plate fixation.

\section{Declaration of conflicting interests}

The authors declared no conflicts of interest with respect to the authorship and/or publication of this article.

\section{Funding}

The authors received no financial support for the research and/or authorship of this article.

\section{REFERENCES}

1. Ekholm R, Adami J, Tidermark J, Hansson K, Törnkvist $\mathrm{H}$, Ponzer S. Fractures of the shaft of the humerus. An epidemiological study of 401 fractures. J Bone Joint Surg [Br] 2006;88:1469-73.

2. Gregory PR. Fractures of the shaft of the humerus. In: Rockwood and Green's fractures in adults. 5th ed. Vol. 1. Philadelphia: Lippincott, Williams \& Wilkins; 2001. p. 974-94.

3. Perren SM. Evolution of the internal fixation of long bone fractures. The scientific basis of biological internal fixation: choosing a new balance between stability and biology. J Bone Joint Surg [Br] 2002;84:1093-110.

4. Firat A, Deveci A, Güler F, Oçgüder A, Oğuz T, Bozkurt M. Evaluation of shoulder and elbow functions after treatment of humeral shaft fractures: a 20-132-month follow-up study. Acta Orthop Traumatol Turc 2012;46:229-36.

5. Healy WL, White GM, Mick CA, Brooker AF Jr, Weiland AJ. Nonunion of the humeral shaft. Clin Orthop Relat Res 1987;219:206-13.

6. Jupiter JB, von Deck M. Ununited humeral diaphyses. J Shoulder Elbow Surg 1998;7:644-53.

7. Atik OŞ. Is there something new and interesting in my article? Eklem Hastalik Cerrahisi 2019;30:69.

8. Volgas DA, Stannard JP, Alonso JE. Nonunions of the humerus. Clin Orthop Relat Res 2004;(419):46-50.

9. Giannoudis PV, Einhorn TA, Marsh D. Fracture healing: the diamond concept. Injury 2007;38 Suppl 4:S3-6.

10. Sarmiento A, Zagorski JB, Zych GA, Latta LL, Capps CA. Functional bracing for the treatment of fractures of the humeral diaphysis. J Bone Joint Surg [Am] 2000;82:478-86.

11. Verbruggen JP, Stapert JW. Failure of reamed nailing in humeral non-union: an analysis of 26 patients. Injury 2005;36:430-8.

12. Flinkkilä T, Ristiniemi J, Hämäläinen M. Nonunion after intramedullary nailing of humeral shaft fractures. J Trauma 2001;50:540-4.

13. Gupta RC, Gaur SC, Tiwari RC, Varma B, Gupta R. Treatment of un-united fractures of the shaft of the humerus with bent nail. Injury 1985;16:276-80.

14. Sügün TS, Ozaksar K, Toros T, Kayalar M, Bal E, Ozerkan F. Humeral shaft nonunions: plates and nails. Eklem Hastalik Cerrahisi 2012;23:150-5.

15. Patel VR, Menon DK, Pool RD, Simonis RB. Nonunion of the humerus after failure of surgical treatment. Management using the Ilizarov circular fixator. J Bone Joint Surg [Br] 2000;82:977-83.

16. Van Houwelingen AP, McKee MD. Treatment of osteopenic humeral shaft nonunion with compression plating, humeral cortical allograft struts, and bone grafting. J Orthop Trauma 2005;19:36-42.

17. Rubel IF, Kloen P, Campbell D, Schwartz M, Liew A, Myers $\mathrm{E}$, et al. Open reduction and internal fixation of humeral nonunions : a biomechanical and clinical study. J Bone Joint Surg [Am] 2002;84:1315-22.

18. Martinez AA, Cuenca J, Herrera A. Two-plate fixation for humeral shaft non-unions. J Orthop Surg (Hong Kong) 2009;17:135-8.

19. Prasarn ML, Ahn J, Paul O, Morris EM, Kalandiak SP, Helfet DL, et al. Dual plating for fractures of the distal third of the humeral shaft. J Orthop Trauma 2011;25:57-63.

20. Metikala S, Bhogadi P. Orthogonal Double Plating and Autologous Bone Grafting of Postoperative Humeral Shaft Nonunion - A Rare Case Report and Review of Literature. J Orthop Case Rep 2015;5:50-3.

21. Kosmopoulos V, Luedke C, Nana AD. Dual small fragment plating improves screw-to-screw load sharing for middiaphyseal humeral fracture fixation: a finite element study. Technol Health Care 2015;23:83-92.

22. Lee SK, Yang DS, Chang SH, Choy WS. LCP metaphyseal plate fixation for fractures of the distal third humeral shaft using brachialis splitting approach. Acta Orthop Belg 2016;82:85-93.

23. Patel R, Neu CP, Curtiss S, Fyhrie DP, Yoo B. Crutch weightbearing on comminuted humeral shaft fractures: a biomechanical comparison of large versus small fragment fixation for humeral shaft fractures. J Orthop Trauma 2011;25:300-5.

24. Capo JT, Debkowska MP, Liporace F, Beutel BG, Melamed E. Outcomes of distal humerus diaphyseal injuries fixed with a single-column anatomic plate. Int Orthop 2014;38:1037-43.

25. Yin $\mathrm{P}$, Zhang L, Mao Z, Zhao Y, Zhang Q, Tao S, et al. Comparison of lateral and posterior surgical approach in management of extra-articular distal humeral shaft fractures. Injury 2014;45:1121-5.

26. Chao TC, Chou WY, Chung JC, Hsu CJ. Humeral shaft fractures treated by dynamic compression plates, Ender nails and interlocking nails. Int Orthop 2005;29:88-91.

27. Spitzer AB, Davidovitch RI, Egol KA. Use of a "hybrid" locking plate for complex metaphyseal fractures and nonunions about the humerus. Injury 2009;40:240-4.

28. Toivanen JA, Nieminen J, Laine HJ, Honkonen SE, Järvinen MJ. Functional treatment of closed humeral shaft fractures. Int Orthop 2005;29:10-3.

29. Jawa A, McCarty P, Doornberg J, Harris M, Ring D. Extraarticular distal-third diaphyseal fractures of the humerus. A comparison of functional bracing and plate fixation. J Bone Joint Surg [Am] 2006;88:2343-7. 